\title{
Crecimiento económico y competitividad en las regiones. Las ciudades medias de Jalisco: el caso de Zapotán El Grande
}

Alejandro Macías Macías*

Resumen: Zapotlán El Grande es una de las cinco ciudades medias de Jalisco que son partícipes del proceso de desconcentración de la actividad económica de la zona conurbada de Guadalajara. Aunque el proceso ha sido lento, estas ciudades necesitan mostrarse atractivas para ser receptoras de los capitales provenientes de la desconcentración. Por ello, es importante estudiar cuáles de estas ciudades presentan mayores ventajas a la inversión en función de su desempeño económico reciente, destaca que Zapotlán El Grande manifiesta puntos débiles al respecto que limitan sus potencialidades de desarrollo, aunque los mismos se pueden revertir en la medida en que $s$ aprovechen sus fortalezas.

Palabras clave ciudad media, región, diversificación, especializa ción,competitividad,vulnerabilidad,desconcentración.

\footnotetext{
* Profesor-Investigador del Centro Universitario del Sur de la Universidad de Guadalajara.Prol. Colón \$ n, Km. 1 carretera Cd. Guzmán-Guadalajara. C. P. 49000, Cd. Guzmán, Jalisco, México. Tel/ Fax (341) 240-44, 251-89, 228-76. Correo electrónico:alejandrom@ cusur.udg.mx
} 
Abstract Zapotlán El Grande is one of the five medium-sized cities in Jalisco involved in the process of deconcentration of economic activity in Guadalajara's conurbated area.Although the process has been slow, these cities need to look attractive in order to receive capitals derived from the deconcentration process. Thus, it is important to know which of these cities offer greater advantages to investment according to their recent economic performance. In this respect, Zapotlán El Grande shows signs of weakness, which limits its potential for development, though this can be changed if its strengths are exploited.

Key words: medium-sized city, region, diversification, specializa tion, competitiviness, vulnerability, deconcentration.

\section{Introducción:}

\section{la viabilidad de las regiones en el mundo globalizado}

En los últimos años, el tema del desarrollo regional ha merecido un análisis importante desde distintas perspectivas que intentan identificar los mecanismos a través de los cuales las regiones pueden crecer en función de las actividades económicas localizadas en ellas. Los estudios de tipo regional se sitúan en la parte intermedia entre el nivel micro de las decisiones de las unidades productivas y el macro de la política nacional, donde la región presenta rasgos homogéneos en su interior, los cuales deben ser observados conjuntamente, pero a la vez heterogé neos con relación a otras zonas.

Podría pensarse que con el advenimiento del paradigma de la globalización, la importancia de estudiar las regiones ha disminuido e incluso podrían considerarse como esfuerzos alejados de 
la realidad, puesto que aspectos que antaño fueron tan importantes para las decisiones de localización de las empresas, como el acceso a los recursos naturales y después la cercanía a los grandes centros de consumo, prácticamente han perdido gran parte de su importancia, ya que el avance en la tecnología del transporte y de las comunicaciones permiten a las empresas ubicarse en lugares alejados de donde se concentran los recursos físicos o el mercado, y aún así ganar ventajas comparativas y competitivas.

Sin embargo, las decisiones de ubicación geográfica siguen siendo de gran relevancia para las empresas, quizá tanto o más que antes, por lo que los estudios regionales mantienen su vigencia y son más pertinentes que antes, pues es en las regiones donde hoy se ubican las principales ventajas competitivas y también donde se manifiesta la gran disparidad que la globalización provoca. En un mundo tan polarizado en todos los sentidos, las regiones que no han sido capaces 0 no tienen los elementos para participar de los beneficios de la economía global cada vez tendrán mayores problemas para aspirar a vencer la pobreza y alcanzar mejores niveles de desarrollo.

Desde el punto de vista económico, los estudios regionales tienen dos aspectos a considerar: uno, el relativo a la importancia de la localización en la competitividad presente; y dos, la manera como las regiones se ven afectadas por estas nuevas formas competitivas y su capacidad para responder a las mismas.

En cuanto al primer punto, si el desarrollo tecnológico en las comunicaciones y los transportes ha disminuido drásticamente la importancia de estar cerca de los centros de abastecimiento y de consumo, ¿por qué sigue siendo la localización tanto 0 más importante que antes?; iqué es lo que determina ahora el que una empresa decida ubicarse en tal o cual lugar? y ¿por qué, lejos de disminuir las diferencias de desarrollo de las regiones, como lo pregona la teoría neoclásica, dados de los rendimientos decrecientes del capital, éstas se han profundizado con la globalización?

La respuesta la podemos encontrar en el siguiente señalamiento de Storper (1997:11): 
Las organizaciones, sobre todo las empresas y grupos o redes de empresas implicados conjuntamente en sistemas de producción, no sólo dependen de contextos territoriales de inputs físicos e intangibles, sino también de las mayores o menores relaciones de proximidad entre cada una

Según Ash Amin (1998:76), la clave de la regionalización actual es que mientras el acceso a la información "codificada" es ca da vez menos costoso y se puede realizar en cualquier parte del mundo, es el conocimiento no codificado el que representa la ma yor fuente de ventajas de una región sobre otra. El conocimiento no codificado - 0 activos relacionales, como Storper (1997:13) lo llama- está constituido por el conocimiento implícito derivado de las relaciones cara a cara, las rutinas establecidas, las costumbres y normas, las convenciones locales respecto a la comunicación, la naturaleza de reciprocidad y la confianza (Amin, 1998:75). En pocas palabras, es el conocimiento que $s e$ da en los arreglos institucionales que existen dentro de cada región y que algunos han identificado con el concepto de capital social.

El objetivo de este artículo no es hacer una reflexión más profunda sobre las implicaciones teóricas y prácticas que tiene el ca pital social, por un lado, y el institucionalismo, por otro, para el desarrollo económico de las regiones ( ya sea en su vertiente de la economía institucional o de la nueva economía institucional, que manejan argumentos un tanto diferentes, e incluso de la crítica que la sociología económica estructuralista ha hecho al manejo atomizado de las instituciones que presenta el neoinstitucionalismo [Granovetter, 1985:56-58]), sino la medición de los indicadores socioeconómicos (y también ambientales, pues éstos cada día son más trascendentes para la viabilidad de una región) que hipotéticamente son reflejo de su presencia o ausencia para, con ba se en ello, hacer inferencias sobre las fortalezas y debilidades del área de estudio comparativamente con otras localidades similares.

Sin embargo, ś es necesario dejar en claro la importancia de las instituciones locales, aś como de los patrones culturales y so- 
ciales que prevalecen en una región determinada, pues de acuerdo con nuestra hipótesis, ellos son uno de los elementos clave pa ra entender la posibilidad de una región para atraer inversiones y para promover su crecimiento y desarrollo socioeconómico. ${ }^{1}$

Ahora bien, es evidente que no todas las regiones cuentan con los activos relacionales propicios a la inversión, lo que nos lleva al segundo aspecto a considerar por los estudios económicos regionales: las regiones se ven afectadas de manera diferente por las nuevas condiciones competitivas. Esto es aś porque, de acuerdo con Castells (1996), lo que sucede actualmente es la generación de redes globalizadas, estructuradas de manera jerárquica, donde existen unos pocos centros nodales, además de regiones de segundo y tercer orden y regiones alejadas de dichas redes.

Antes de explicar los anteriores tipos de regiones de acuerdo con su posición estratégica en las redes competitivas globales, cabe hacer una aclaración. Aquí nos referiremosa la región como si fuera un ente vivo con características propias y capacidades de cambio intrínsecas. Evidentemente esto no es así; los entes vivos son los actores sociales que forman parte de ella, ya sea porque ahí habiten o porque en ella generen procesos socioeconómicos importantes. En cuanto a la capacidad de cambio, queda claro que tal capacidad depende de condiciones externas hasta cierto punto ajenas a los actores sociales de la región, pero también a aspectos internos,como son el marco institucional, económico, social, político y cultural que exista en la región, que puede ser propicio al cambio 0 un freno al mismo. Sin embargo, tratar a las regiones como si fue-

\footnotetext{
1 Señalo que es uno de los aspectos clave porque una región sin recursos materiales acordes a la competitividad, por más que tenga instituciones propicias al desa rrollo y capital social, seguirá ajena a las redes globales, batallando para poder crecer. Por tanto, aunque el capital social puede cumplir la función básica de atraer las inversiones foráneas, tal como lo señala Putnam (1993), una comunidad que tenga una red social muy recíproca, muy rica en capital social, pero que carezca de recursos económicos no logrará el éxito (Portes y Landolt, 1996). Por lo tanto, para alcanzar el crecimiento económico se requiere que la región cuente con capital social, recursos económicos,capital humano y rasgos culturales que se fortalezcan unos a otros, y que ello fomente la innovación y la inversión.
} 
ran entes vivos sólo tiene como objetivo simplificar la presenta ción. Al fin y al cabo las regiones son constructos analíticos que permiten "explicar las relaciones entre tres variables clave en las ciencias humanas: el cambio sociocultural, el espacio y el tiempo" (Van Young, 1992:4).

Hecha tal aclaración, regresamos a explicar las distintas posiciones que pueden guardar las regiones en el mundo competitivo actual. Los centros nodales son áreas privilegiadas donde las empresas buscarán instalar la parte más importante de su estructura de red. Las regiones que presentan tales características adquieren una ventaja competitiva de largo plazo que les facilitará ser artífices de su propio proyecto de desarrollo y les permitirá asumir un papel estratégico en el mundo competitivo globaliza do. Estas regiones normalmente se ubican en los páses más desa rrollados (en ciudades como NuevaYork, Londres, Tokio, etcétera, en el área financiera 0, por ejemplo, Silicon Valley, en el aspecto tecnológico). En el segundo nivel,se ubican las regiones dependientes que abastecen a estos centros nodales, mientras que en el tercer nivel están las que sirven de apoyo a las regiones de segundo nivel. Finalmente, se encuentra la gran mayoría de regiones de los países en vías de desarrollo o subdesarrollados que están fuera de las redes y son afectadas negativamente por el mundo global. Fernando Enrique Cardoso (1992, cit por Castells, 1996:160), menciona que algunas de estas regiones y mucha de su gente no serán "ni siquiera consideradas dignas de las molestias de la explotación y se volverán irrelevantes y carentes de interés para la economía globalizada en desarrollo".

Esto nos lleva a una creciente desigualdad entre las distintas regiones, de acuerdo con su situación en los tres criterios siguientes. 1) si están insertas o no en una red; 2) si lo están, cuáles son los alcances competitivos de la red; $y, 3$ ) qué posición ocupa la región dentro de esa red, así como los nexos con los otros miembros de la red y con redes externas. Por lo tanto, estamos ante un mundo polarizado, donde existen varios centros y varias periferias dentro de cada país. Pero es a la vez un mundo dinámico don- 
de la ubicación de cada región no es permanente, sino que puede aumentar o disminuir en su jerarquía de acuerdo con las condiciones internasy externas de su red y de la relación con las otras redes. En este contexto, las ciudades medias, ya no en el ámbito nacional sino en el plano estatal, como la que en este trabajo se analiza, son poblacionesque quizá se encuentren en unatercerajerarquía dentro de una red e inclusive puede ser que se ubiquen en un nuevo cuarto nivel jerárquico, o que apenas estén queriendo entrar a una red. Pero para ello, la región debe tener las condiciones socioeconómicas propicias para atraer inversiones y para que sus principales actores sociales se desarrollen. En lo que resta de este trabajo presentaré una evaluación de los principales indicadores económicos, pero también de algunos ambientales de Ciudad Guzmán, ubicada en el municipio de Zapotlán El Grande y que es una de las ciudades medias en el estado de Jalisco. Antes permítaseme hacer una pequeña reseña de la evolución que ha tenido el concepto de ciudades medias en México.

\section{Las ciudades medias en el desarrollo de México}

México ha sido un país cuyo desarrollo en el siglo xx estuvo caracterizado por la elevada concentración de recursos y proyectos en unas cuantas grandes metrópolis. El modelo de sustitución de importaciones, seguido por el país desde el término de la Segunda Guerra Mundial y hasta la crisis de la deuda en 1982, exigía la existencia de grandes centros urbanos que fueran atractivos para el establecimiento de empresas trasnacionales que los demandaban tanto por la concentración de mercados concentrados como mano de obra disponible e infraestructura urbana adecuada a sus necesidades Además, tal modelo, estaba por su naturaleza, orientado hacia el mercado interno urbano a fin de obtener economías de escala y rendimientos atractivos que permitieran el desarrollo de una estructura industrial y de servicios apropiada. 
De 1960 a 1980, la Ciudad de México pasó de 5.4 a 13 millones de habitantes, y otras tres ciudades ( Guadalajara, Monterrey y Puebla) superaron el millón de habitantes (Garza, 1998:23). En este contexto, el crecimiento urbano de estas poblaciones no puede resultar sorprendente para nadie, sino que tiene una explica ción lógica de acuerdo con la forma en que se planteó el modelo de desarrollo en México.

Sin embargo, a finales de la década de los sesenta, tal crecimiento comenzó a salirse de los controles estatales, de modo que, en los años siguientes, las grandes metrópolis mexicanas pasaron de las economías de aglomeración a las economías de scturación, provocando problemas como el crecimiento desordenado de los núcleos poblacionales, la incapacidad del Estado para satisfacer las necesidades crecientes de servicios públicos, de salud, educativos e infraestructura adecuada, con la consecuente generación de círculos de pobreza.

La década de los ochenta, llamada la "década perdida" para América Latina, puso de manifiesto las deficiencias que el modelo de sustitución de importaciones había generado en el desarrollo del sistema urbano de México. En esa década se profundiza el cuestionamiento sobre la concentración poblacional en pocos núcleos y, en contraste, la gran dispersión rural existente en el pás, disminuyen la capacidad del Estado para satisfacer todas las necesidades de la población. Sin embargo, es en la década de los noventa cuando se plantea como una prioridad nacional la búsqueda de un proceso desconcentrador de las grandes metrópolis. Aś, las ciudades de más de un millón de habitantes pasaron de 4 a 6 entre 1980 y 1995 y las que tenían más de 500 mil habitantes y menos de 1 millón, pasaron de 4 a 18 en ese mismo lapso.

Estas últimas se consideraron como las ciudades medias de México que debían ser atendidas para que se convirtieran en los centros urbanos capaces de consolidarse como polos de desarrollo de sus respectivas regiones. No obstante lo anterior, de acuerdo con Gustavo Garza (1998:24-25), las ciudades medias que más han crecido en los últimos años, son núcleos que se encuentran ínti- 
mamente asociados con las grandes metrópolis (Cuernavaca, Querétaro y Toluca con la Ciudad de México; Aguascalientes y León con Guadalajara, y Saltillo con Monterrey) o bien que son enclaves maquiladores de la megalópolis de California cuyo centro es Los Ángeles (como son los casos deTijuana o Mexicali).

Aún aś, el discurso gubernamental de Ernesto Zedillo (19942000) y Vicente Fox (2000-2006) han puesto énfasis en la necesidad de impulsar a las ciudades medias como un vehículo necesario para fomentar un mejor desarrollo regional de México y contribuir a disminuir las presiones sobre las grandes urbes. Un documento publicado por la Secretaría de Desarrollo Social en noviembre de $\mathbf{2 0 0 0}$ (al final de la administración zedillista) literalmente dice lo siguiente:

México padece fuertes desequilibrios en la distribución de su población y de las actividades económicas en el territorio. Una expresión de esto es la excesiva concentración de los habitantes en unos cuantos centros urbanos que crecen de manera de sordenada, lo cual contrasta con la gran dispersión que se observa en el medio rural.

Los costos de estos desequilibrios son cada vez mayores en términos de calidad de vida y bienestar social de la población, de alteraciones ecológico-ambientales y de pérdida y degrada ción de recursos naturales. Son también un obstáculo para el cabal aprovechamiento del potencial que tiene México en los circuitos comerciales y productivos de la actual economía mundial (SEDESOL, 2000:1).

Por ello, el Plan Nacional de Desarrollo 1995-2000 (1995:108) habla de la necesidad de apoyar a 116 ciudades medias estratégicas con los siguientes objetivos:

- Recuperación de la capacidad local para regular el desarrollo urbano y dar viabilidad a las actividades económicas a media no plazo; 
- Identificación y promoción de ciudades medias con potencial para recibir inversiones y población; e,

- Impulso al desarrollo regional y al ordenamiento territorial (SEDESOL, 2000:6)

De igual manera, el Plan Nacional de Desarrollo 2001-2006 (2001:121), aunque no habla precisamente de desarrollar determinadas ciudades medias, sí establece la necesidad de promover un desarrollo regional equilibrado mediante el apoyo especial a las regiones más rezagadas.

Ahora bien, ¿qué entendemos por ciudades medias? El desarrollo urbano se puede entender mediante la clasificación de las ciudades en metrópolis, ciudades medias y ciudades pequeñas. De acuerdo con Margarita Estrada (cit. por Haydeé García, 1997), el concepto de ciudad media es más bien descriptivo que analítico, siendo el "conjunto de procesos sociales, económicos, políticos y culturales que son específicos de las ciudades que, sin ser pequeñas comunidades, tampoco son grandes metrópolis". Es decir, son espacios urbanos que adquieren, debido a lo anterior, una significación propia.

Por lo tanto, la definición de ciudad media tendrá que partir de la correspondiente clasificación que el investigador haga para tipificar también a las metrópolis y a las pequeñas ciudades. Así por ejemplo, el Instituto de Transporte de Texas (cit. por Rodrigo Quijada, 2001) define como ciudad media a aquélla que tiene entre $\mathbf{5 0 0}$ mil y un millón de habitantes. De igual manera, el Plan Nacional de Desarrollo 1995-2000 establece como ciudad media el mismo rango, aunque para Gustavo Garza (1998:24), las ciudades medias son las que se ubican en el rango entre los 50 mil y los $\mathbf{5 0 0}$ mil habitantes. Otras clasificaciones de ciudades medias son las que las ubican en el rango entre los 50 mil y los $100 \mathrm{mil}$ habitantes (CEO, 2001).

Por lo que se puede observar, no existe una clasificación de ciudad media globalmente aceptada, más bien depende del universo que se está estudiando. Sin embargo, una tipología interesante es la que se observa en el Plan de Desarrollo Urbano del 
Estado de San Luis Potoś, 2000-2020, el cual establece seis rangos para dividir a los núcleos poblacionales que van desde una metrópoli con población superior al millón de habitantes hasta la población rural que tiene menos de 2500 habitantes.

En este documento se pueden identificar ciudades medias con proyección regional y ciudades medias con relevancia estatal. Las ciudades medias con proyección regional serían "aquéllas que $\mathbf{s e}$ estructuran como enlace principal entre ciudades medias de otros estados y los centros urbanos relevantes en el estado. [...] Su importancia radica en su contribución a consolidar los corredores económicos estatales".

Por su parte, las ciudades medias con proyección estatal serían las que " $\$$ estructuran como enlace entre varias microrregiones del estado y de otros estados. Su importancia radica por los servicios que proporcionan a todos los núcleos poblacionales de varias microrregiones".

Con respecto a Jalisco, si consideramos las ciudades medias como las que están entre los 500 mil y el millón de habitantes, este estado no tendría ninguna, dado el proceso de excesiva concentración poblacional en la ciudad de Guadalajara y su zona conurbada. Por lo tanto, para efectos de este estudio consideramos ciudad media como aquella que tiene más de 50 mil habitantes, exceptuando a los munici pios que conforman la zona conurbada de Guadalajara, pues ellos han seguido la dinámica de crecimiento de Guadalajara, como se verá mas adelante.

Con ese criterio, las ciudades medias de Jalisco (en la escala estatal) son: Puerto Vallarta, Lagos de Moreno, Tepatitán, Ciudad Guzmán (en el municipio de Zapotlán El Grande) y Ocotlán, todas ellas consideradas por $\mathrm{a}$ Gobierno de Jalisco como polos de desa rrollo de sus respectivas regiones (véase mapa). Además, existen otros municipios que son polos de desarrollo y que como municipios superan los cincuenta mil habitantes. Sin embargo, en esos casos su cabecera municipal no llega a esa cifra, por lo que, para efectos de este trabajo, no serán considerados como ciudades medias. 
Además, siguiendo los criterios del Plan de Desarrollo Urbano del Estado de San Luis Potosí,2000-2020, Ciudad Guzmán es una ciudad media con proyección estatal, pues es polo de enlace del sur de Jalisco con la ciudad de Colima en el estado del mismo nombre.

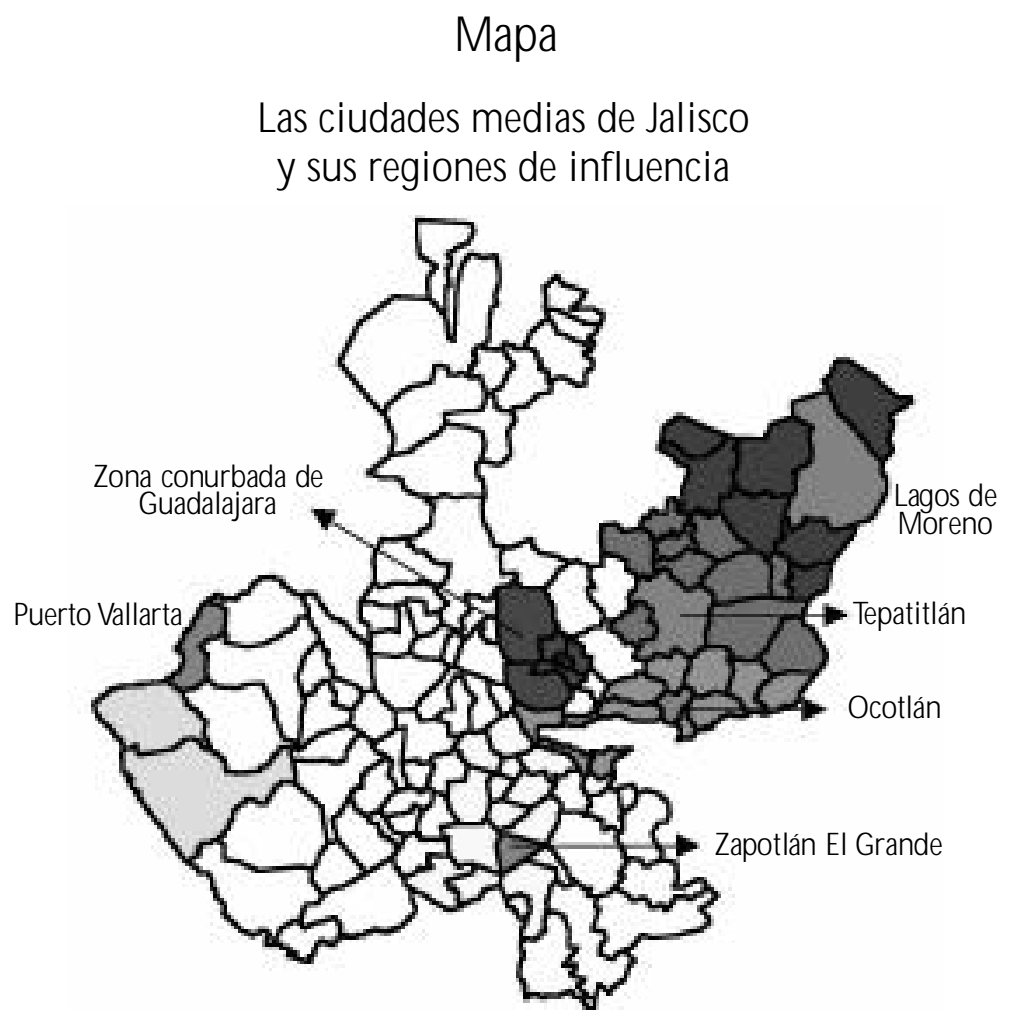

Las ciudades medias de Jalisco

Jalisco es uno de los estados más industrializados del país al participar con $6.4 \%$ del producto interno bruto (PIB) nacional, por lo 
cual ocupa el cuarto lugar en importancia en este rubro, aunque en 1994 estaba en tercero (INEGI, 2002). Junto con su principal ciudad - Guadalajara- , Jalisco ha sido históricamente el polo de desarrollo de la región centro-occidente de México, ${ }^{2}$ pues en 1998 concentró 33\% de las unidades económicas de la región y $38 \%$ del empleo (INEGI, 2001). La dinámica económica del estado se inscribe en el corredor que parte de Nuevo Laredo en la frontera con los Estados Unidos hasta el principal puerto de cabotaje del Pacífico mexicano, es decir, Manzanillo en Colima. En Jalisco, el pa trón de desarrollo ha estado enmarcado por la concentración de la población y de la actividad económica en Guadalajara y recientemente en su zona conurbada (compuesta por Zapopan,Tlaquepa que, Tonalá, Tlajomulco y El Salto, además de Guadalajara). En 1970, Guadalajara concentraba $61 \%$ de la población económica mente activa ocupada (PEAO) dedicada a los sectores urbanos ${ }^{3}$ en el estado (INEGI, 1970). Para el año 2000, si bien la cifra ha disminuido a $32 \%$, este proceso de desconcentración es relativamente ficticio, pues la mayor parte de ella se da hacia su zona conurba da, de manera que al considerarla en conjunto, tenía en 1970 el $72 \%$ de la mano de obra urbana del estado y en el 2000 el $68 \%$. Esto nos lleva a observar un lento proceso de difusión de las actividades de mayor valor agregado hacia otras regiones del estado. Todavía hoy, el gobierno de Jalisco reconoce en su Plan Estatal de Desarrollo 2001-2006 los problemas que para el estado tiene la gran aglomeración de Guadalajara ( $54 \%$ de la población estatal,

2 De acuerdo con el Plan Nacional de Desarrollo 2001-2006, la región centro-occidente de México quedó conformada por los estados de Jalisco, Michoacán, Nayarit, Colima,Guanajuato, Zacatecas, Aguascalientes y San Luis Potosí. Esta regionalización es distinta a la región occidente del sexenio de Ernesto Zedillo, que sólo comprendía los cuatro primeros estados mencionados con anterioridad y que en ese caso la participación de Jalisco sería de $55 \%$ en unidades económicas y $64 \%$ en personal ocupado (INEGI, 2001).

3 Cuando se habla de mano de obra urbana, se refiere a la población económica mente activa que $s$ dedica a actividades del sector manufacturero 0 bien de servicios y comercio. Se parte de que estas son las actividades que mayor valor agregado generan y, por lo tanto, son detonantes de un crecimiento más dinámico. 
$70 \%$ de la industria, $60 \%$ del comercio y más de $80 \%$ de la educación superior) y la extrema dispersión que presenta la pobla ción rural, ya que 1.2 millones de jaliscienses viven en más de ocho mil localidades menores de cinco mil habitantes.

Adicionalmente, a mismo plan reconoce como un problema fundamental "la carencia de verdaderas ciudades medias en el sistema urbano estatal [pues] si bien existen 39 localidades mayores de $\mathbf{1 5}$ mil habitantes, de las cuales nueve tienen más de $\mathbf{5 0}$ mil habitantes, éstas se encuentran lejos de ofrecer alternativas reales a la atracción de Guadalajara" ( Gobierno del Estado de Ja lisco, 2001:186).

No obstante, Puerto Vallarta, Lagos de Moreno, Tepatitlán, Za pottán $\mathrm{E}$ Grande y Ocotlán han evolucionado positivamente en los últimos años hacia el sector manufacturero, de servicios y comercio, ganando espacios y consolidando su situación como ciudades medias (por lo menos en una escala estatal), ya que han pasado de tener en 1980 el $7 \%$ de la población ocupada del estado en estas actividades a 10\% en el 2000 (cuadro 1). Además, de 1980 a 1990 , mientras que Guadalajara creció en $3 \%$ promedio anual en la mano de obra ocupada en actividades urbanas, los municipios mencionados lo hicieron en $8 \%$ y Puerto Vallarta en $12 \%$, dando cuenta del dinamismo y representatividad que estas ciudades adquirieron en los años ochenta y que se confirmó en la década sguiente, periodo en el que las ciudades medias mantuvieron una tasa promedio de crecimiento anual de $6 \%$ ( $8 \%$ en el caso de Puerto Vallarta), por $5 \%$ de la zona conurbada de Guadalajara y Jalisco 4 (cuadro 1). De esta forma, pese a que Jalisco ha sido tradicionalmente un estado expulsor de población rural hacia las grandes ciudades del país (principalmentela propia Guadalajara) y los Estados Unidos (Arroyo y Velásquez, 1997), las tendencias desconcentra

\footnotetext{
${ }^{4}$ Aunque los municipios de la zona conurbada de Guadalajara siguen siendo más dinámicos. En la década de los ochenta, Tonalá creció $17 \%$ promedio anual en ese decenio, El Salto $11 \%$, Tlaquepaque y Zapopan $10 \%$ y Tlajomulco $9 \%$. Mientras, en la última década, El Salto y Tonalá crecieron $11 \%$ promedio anual,Tlajomulco $10 \%$, Za popan $7 \%$ y Tlaquepaque $6 \%$. Sólo Guadalajara creció a una tasa inferior a 3\%.
} 


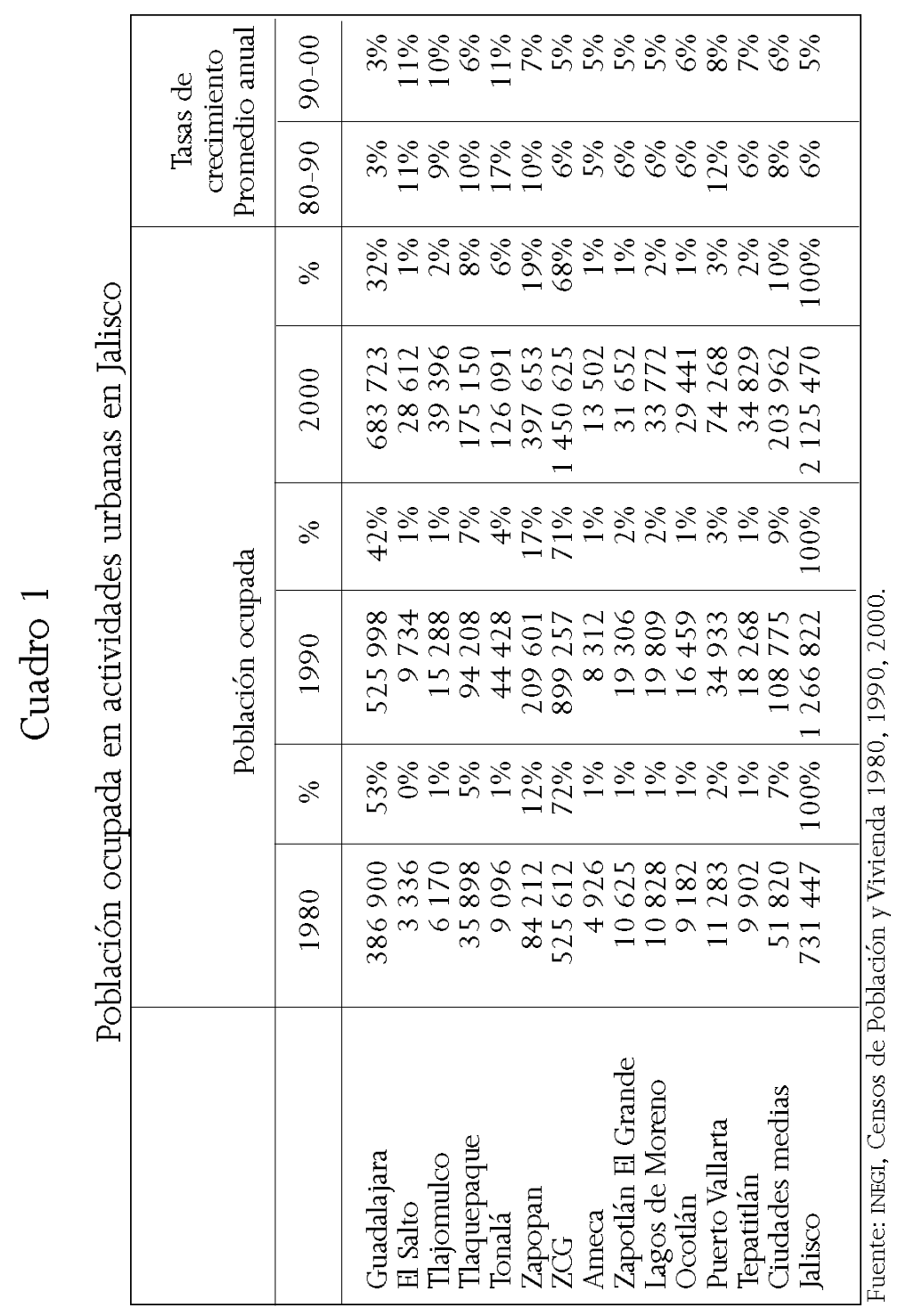


doras en las ciudades medias permiten augurar que este fenómeno pueda revertirse en los próximos años. En el caso de Zapottán El Grande, éste se consolida como el polo de desarrollo de la región sur y sureste de Jalisco al aglutinar, en el año 2000, el $20 \%$ de la población regional, además de que en 1998 concentró 36\% de las unidades económicas y $30 \%$ de la población económica mente activa de estas dos regiones ( $10 \%$ en el sector primario, $30 \%$ en el secundario y $47 \%$ en el terciario ${ }^{5}$ ). Además, la pobla ción del municipio ha crecido en $\mathbf{1 . 5 7 \%}$ promedio anual en los últimos diez años a pesar de que la región sólo lo ha hecho en 0.48\% (INEGI, 2000). Zapotlán El Grande es un municipio que ca da vez más se especializa en servicios y comercio; si en 1970 aglutinaba 44\% de la PEAO regional en este sector, para 1990 la cifra aumenta a $47 \%$ y para el 2000 llega hasta $68 \%$.

\section{Diversificación y especialización productiva en las ciudades medias de Jalisco}

Si bien es cierto que el proceso de desconcentración de la zona conurbada de Guadalajara hacia las ciudades medias de Jalisco es lento, en los últimos años se empieza a manifestar cierto dinamismo que las vuelve atractivas no sólo para frenar la migración sino también para fomentar la inmigración, ya que mientras la población en Jalisco creció a una tasa promedio anual de $1.74 \%$ entre 1990 y el 2000, estas ciudades lo hicieron en promedio a una tasa de $2.61 \%$ (aunque hay una gran diferencia entre ellas, pues Puerto Vallarta creció más de $5 \%$ anual y Zapotlán El Grande lo hizo 1.57\%).

En cuanto a los municipios donde se ubican las ciudades medias, se puede observar que hasta 1990, todos conservaban un es-

\footnotetext{
5 El sector primario comprende agricultura, ganadería, minería, pesca; el secundario, las actividades manufactureras, en tanto que el terciario incluye servicios y comercio.
} 
tatus de municipios semiurbanos, ${ }^{6}$ pese a que 10 años antes Lagos de Moreno y Tepatitán tenían el carácter de semirurales Sin embargo, para el año 2000 se consolida el proceso de urbanización de las ciudades medias al ser Puerto Vallarta ya un municipio urba no;Zapotlán El Grande y Ocotlán aglutinan más de $90 \%$ de su PEAO en manufacturas, servicios y comercio, en tanto que Lagos de Moreno y Tepatitlán tienen 81 y 78\%, respectivamente, sobre todo porque estos dos municipios son polos de desarrollo de una de las regiones agroindustriales más importantes del país (principalmente en la producción de lácteos y la avicultura). En el dinamismo económico de las ciudades medias, Puerto Vallarta tiene ciertas particularidades, pues su desarrollo no obedece a un proceso de desconcentración en el estado, sino a su singularidad como centro turístico a nivel nacional. En los otros cuatro municipios sí puede existir esta dinámica aunque también es consecuencia de las características propias de su ubicación geográfica y de las relaciones que mantienen con otros estados de la república, como por ejemplo Lagos de Moreno, cuya actividad económica está fuertemente relacionada con lo que sucede en la ciudad de León, Guanajuato, y tiene fuertes nexos con estados como Aguascalientes o San Luis Potosí, o bien, Zapotlán El Grande, que mantiene estrechas rela ciones con la ciudad de Colima.

En cuanto a la diversificación de las actividades económicas urbanas, se observa cómo todas las ciudades medias, con excepción de Ocotlán, han aumentado su nivel entre 1993 y 1998. Incluso Puerto Vallarta, que era en 1993 un municipio muy poco diversi-

6 Los criterios que se utilizan en este artículo para definir los niveles de urbanización de los municipios son los siguientes:

$>0$ por ciento y < 3 por ciento de población económicamente activa ocupada (PEAO) en actividades del sector primario: municipio urbano;

$>\mathbf{3}$ por ciento $\mathrm{y}<\mathbf{4 0}$ por ciento de PEAO en el sector primario: municipio semiurbano;

$>40$ por ciento y < 70 por ciento de PEAO en el sector primario: municipio semirural;

$>70$ por ciento de de PEAO en el sector primario: municipio rural. 
ficado (por su fuerte orientación hacia el turismo), para 1998 mejoró considerablemente en esta situación (cuadro 2).

\section{Cuadro 2}

Porcentaje de diversificación en actividades económicas urbanas de las ciudades medias de Jalisco*

\begin{tabular}{|l|c|c|c|c|}
\hline Municipio & \multicolumn{2}{|c|}{1993} & \multicolumn{2}{c|}{1998} \\
\hline & $\%$ & Lugar en Jalisco** & $\%$ & Lugar en Jalisco \\
\hline Lagos de Moreno & 22 & 19 & 28 & 9 \\
Ocotlán & 22 & 19 & 21 & 24 \\
Puerto Vallarta & 12 & 94 & 19 & 39 \\
Tepatitán & 28 & 8 & 32 & 4 \\
Zapotlán El Grande & 29 & 6 & 30 & 6 \\
\hline
\end{tabular}

* Se consideró como criterio las ramas económicas manejadas por el INEGI en los respectivos Censos Económicos, donde el municipio tuviera aunque fuera una leve especialización.

Para la determinación de las ramas económicas donde el municipio tuviera especialización se utilizó la metodología señalada en el anexo I.

** En Jalisco hay 124 municipios.

Fuente: elaborado con base en INEGI, Censos Económicos de 1994 y 1999.

Por su parte, Tepatitán se ubicó en el cuarto lugar de diversificación y Zapotán El Grande en el sexto, sólo superados por Guadalajara (91\%), Zapopan (87\%), Tlaquepaque (40\%) y Tla jomulco (31\%).

Pese a la diversificación de Zapotlán El Grande en general, en lo que se refiere a sectores económicos, la situación cambia, pues $s i$ consideramos sólo al sector manufacturero, este municipio se ubica en el lugar 18 a nivel estatal por debajo de Lagos de Moreno (8) y Tepatitlán (9), aunque en mejor posición que Ocotlán (29) y Puerto Vallarta (119). En cuanto a comercio, Zapotlán El Grande ocupa el quinto lugar del estado, al igual queTepatitán (Puerto Va- 
llarta es el 8, Ocottán el 22 y Lagos de Moreno el 27). Finalmente, en servicios Zapotlán es el tercer municipio de Jalisco con ma yor porcentaje de ramas en que tiene cierta especialización con $46 \%$, sólo por debajo de Guadalajara y Zapopan.Aquí, Tepatitlán está en el lugar 5, Puerto Vallarta en el 7, mientras que Lagos de Moreno y Ocottán ocupan el lugar 26. Sin embargo, pese a que es claro cómo Zapotán El Grande se orienta hacia los servicios y el comercio, el cuadro 3 muestra que no tiene una sola rama económica urbana de gran relevancia, lo que resulta una desventaja respecto a sus perspectivas a futuro, toda vez que se considera que en el tránsito hacia el desarrollo de las ciudades, la primera etapa es pasar de actividades productivas primarias hacia manufactureras y el siguiente consiste en especializarse en servicios, pero siempre y cuando éstos sean de alto valor agregado.

En este sentido, se podría pensar que el proceso de desconcentración que vive Jalisco está caracterizado por el traslado de muchas de las industrias manufactureras de Guadalajara a otros municipios del estado; por ello, las ciudades medias deberían crecer en su actividad manufacturera. Sin embargo, Zapotlán El Grande, a diferencia de la mayoría de las otras ciudades medias, no ha tenido ese tránsito, pues aunque las actividades primarias (con excepción del ganado lechero o de la producción de miel) no son ya de gran importancia, las manufacturas no se han desarrollado como se pudiera esperar y los servicios no son de gran valor agregado, ya que a grueso de ellos se concentra sobre todo en el comercio de alimentos. Todo esto nos lleva a ver que Zapottán El Grande se encuentra en una posición de desventaja en cuanto a sus perspectivas de desarrollo con relación a las otras ciudades medias. Si observamos el cuadro 3, mientras los otros cinco municipios estudiados tienen varias ramas de alta especialización en manufacturas y/ 0 servicios y algunos de ellos conforman clusters $^{7}$ de importancia estatal e in-

7 De acuerdo con Michael Porter (1999:203), los clusters son concentraciones geográficas de em presas interconectadas, suministradores especializados, proveedores de servicios, empreses de sectores afines e instituciones conexas que compiten pero que también cooperan. 


\section{Cuadro 3}

\section{Ramas productivas urbanas de alta especialización en las ciudades medias de Jalisco (1988)}

\begin{tabular}{|c|c|c|}
\hline Municipio & Manufacturas & Servicios y comercio \\
\hline Zapotlán El Grande & $*$ & $*$ \\
\hline Lagos de Moreno & $\begin{array}{c}\text { Elaboración de productos } \\
\text { lácteos; elaboración de } \\
\text { alimentos preparados para } \\
\text { animales; prendas de vestir; } \\
\text { fundición de } \\
\text { metales; maquinaria. }\end{array}$ & Hoteles \\
\hline Ocotlán & $\begin{array}{c}\text { Alimentos para animales; } \\
\text { fabricación y reparación de } \\
\text { muebles, } \\
\text { principalmente de madera. }\end{array}$ & Servicios domésticos \\
\hline Puerto Vallarta & $*$ & $\begin{array}{c}\text { Supermercados; } \\
\text { autotransporte pasajeros; } \\
\text { transporte por agua;; } \\
\text { transporte aéreo; } \\
\text { servicios inmobiliarios; } \\
\text { restaurantes, bares y } \\
\text { centros nocturnos; } \\
\text { hoteles y otros servicios } \\
\text { de alojamiento } \\
\text { temporal; servicios } \\
\text { relacionados con } \\
\text { transporte por agua; } \\
\text { servicios relacionados } \\
\text { con transporte aéreo; } \\
\text { servicios de agencias de } \\
\text { viajes y almacenaje. }\end{array}$ \\
\hline Tepatitlán de Morelos & $\begin{array}{l}\text { Alimentos para animales; } \\
\text { confección con materiales } \\
\text { textiles, incluye la } \\
\text { fabricación de tapices y } \\
\text { alfombras; prendas de } \\
\text { vestir; maquinaria. }\end{array}$ & $*$ \\
\hline
\end{tabular}

* Para la determinación de las ramas económicas donde el municipio tuviera especialización, se utilizó la metodología señalada en el anexo I.

Fuente: elaborado con base en INEGI, Censos Económicos de 1998. 
cluso nacional, como la agroindustria láctea 0 avícola en Lagos de Moreno y Tepatitán, la industria textil en estos mismos municipios, el cluster mueblero en Ocotlán o el turístico en Puerto Vallarta, en Zapottán El Grande no existe una rama económica de tal magnitud, aun cuando existen dusters reales y potenciales pero que no están consolidados como para tener mayor trascendencia en el estado.8 Por ejemplo, el cluster lácteo de Zapotlán y el sur de Jalisco tiene muchas ramificaciones, pero es mucho menos sólido si se compara con el de la región de LosAltos (Lagos de Moreno y Tepatitlán como polos de desarrollo). Esto provoca que Zapotlán El Grande sea más vulnerable para enfrentar las demandas competitivas de la globalización.

De igual forma, los datos expresados en el cuadro 4 son indicativos de la clara desventaja que este municipio tiene con respecto al resto de las ciudades medias, pues si bien es cierto que después de Puerto Vallarta,Zapotlán El Grande es el municipio con mayor número de unidades económicas de los cinco estudiados, la situación respecto al personal ocupado y a los indicadores de tipo económico financiero, lo ubican en el último lugar.

En el caso del tamaño de empresas promedio, medido por el número de trabajadores por compañía, el cuadro 4 destaca cómo en términos generales Jalisco es un estado con fuerte presencia de las microempresas, ya que tiene un promedio inferior a 5 trabajadores por cada unidad económica. Esto se confirma en el caso de sus ciudades medias, pues sólo Puerto Vallarta tiene un promedio superior al estatal, y dentro de ellos, Zapotlán El Grande es el que presenta el promedio más bajo.

En cuanto a los indicadores de tipo económico, resulta muy claro que Zapotlán El Grande se encuentra en clara desventaja. Por ejemplo, en la producción promedio por empresa, mientras a nivel estatal hablamos de 1.2 millones de pesos por empresa y exis ten municipios como Lagos de Moreno o Puerto Vallarta que superan el millón de pesos, Zapotán El Grande apenas tiene un

\footnotetext{
8 Véase un análisis de los clusters de Zapotlán El Grande en Macías (2003).
} 


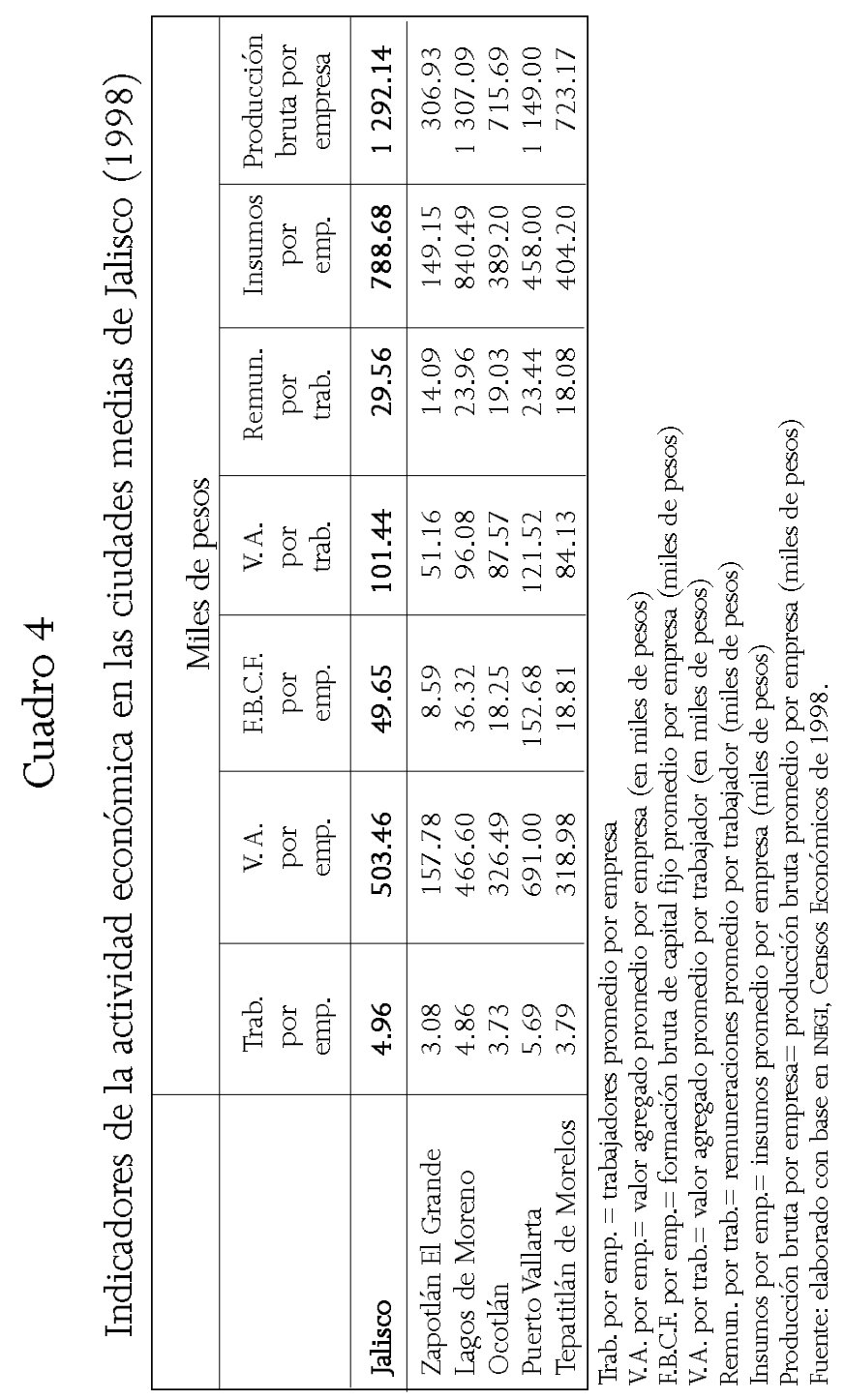


promedio de poco más de 300 mil pesos por empresa (cuadro 4). La misma situación se da en el resto de los indicadores, para casi todos, Zapottán El Grande presenta datos apenas de la mitad con respecto al municipio que le antecede.

Lo anterior deja ver que en Zapotlán El Grande no existe una sola industria con empresas grandes, como se dan en los otros municipios (Puerto Vallarta con sus hoteles, Lagos de Moreno y Tepatitán con su agroindustria, Ocottán con empresas como $\mathrm{Ce}$ lanese, Nestlé o con la industria mueblera en crecimiento). Combinando lo anterior con el hecho de que este municipio no presenta ramas de alta especialización, hace más que claras sus desventajas en la lucha por atraer los capitales que se desconcentran de Guadalajara y quieren invertir en Jalisco.

En el cuadro 5, aparecen las ramas económicas líderes en las ciudades medias de Jalisco de acuerdo con tres indicadores. En él se corrobora cómo Zapotlán El Grande queda muy lejos de cualquiera de los otros municipios. Además, como se verá enseguida, las ramas económicas líderes en Zapotlán no son de ninguna manera en las que este municipio se especializa, pues celulosa y papel son más bien es un apéndice de la actividad que en ese sentido se desarrolla en el municipio deTuxpan. Prueba de ello es que sólo da empleo a 77 personas ( $0.6 \%$ de la PEAO municipal en actividades urbanas) y genera menos de $2 \%$ de la producción total municipal. De igual forma, la producción de cemento y cal es consecuencia de la actividad que se realiza de manera importante en el municipio vecino de Zapotiltic; incluso sólo da empleo a 149 personas aunque genera casi $10 \%$ de la producción urbana municipal.

De hecho, las ramas con mayor número de empresas en $\mathrm{Za}$ potlán El Grande son el comercio alimenticio y no alimenticio en establecimientos especializados, los cuales en conjunto corresponden a $44 \%$ del total de compañías. Sin embargo, en promedio, las empresas de estas dos ramas tienen entre uno y dos trabajadores, es decir, son microempresas que no poseen la fuerza necesaria para impulsar el desarrollo económico local. 


\section{Cuadro 5}

Ramas económicas líderes en las ciudades medias de Jalisco (1998)

\begin{tabular}{|c|c|c|c|c|c|c|}
\hline & \multicolumn{2}{|c|}{ Trab. por empresa } & \multicolumn{2}{|c|}{ V. A. por empresa } & \multicolumn{2}{|c|}{ Prod. por empresa } \\
\hline & Rama & No. & Rama & No. & Rama & No. \\
\hline Jalisco & $\begin{array}{c}\text { Rama } 3823 \\
\text { Fabricación y/ o } \\
\text { ensamble de } \\
\text { máquinas } \\
\text { de oficina } \\
\text { cálculo y } \\
\text { procesamiento } \\
\text { informático }\end{array}$ & 474 & $\begin{array}{c}\text { Rama } 3140 \\
\text { Industria del } \\
\text { tabaco }\end{array}$ & 361177 & $\begin{array}{c}\text { Rama } 3823 \\
\text { Fabricación y/ o } \\
\text { ensamble de } \\
\text { máquinas } \\
\text { deoficina, } \\
\text { cácculo y y } \\
\text { procesamiento } \\
\text { informático }\end{array}$ & $\begin{array}{c}1775 \\
816\end{array}$ \\
\hline Zapotlán El Grande & $\begin{array}{c}\text { Rama } 3410 \\
\text { Manufactura de } \\
\text { celulosa, } \\
\text { papel y sus } \\
\text { productos }\end{array}$ & 33 & $\begin{array}{c}\text { Rama } 3691 \\
\text { Fabricación } \\
\text { de cemento, } \\
\text { cal, yeso y } \\
\text { otros productos } \\
\text { a base de } \\
\text { minerales } \\
\text { no metálicos }\end{array}$ & 3938 & $\begin{array}{c}\text { Rama } 3691 \\
\text { Fabricación } \\
\text { de cemento, } \\
\text { cal, yeso y } \\
\text { otros productos } \\
\text { a base de } \\
\text { minerales } \\
\text { no metálicos }\end{array}$ & 8748 \\
\hline Lagos de Moreno & $\begin{array}{c}\text { Rama } 3220 \\
\text { Confección de } \\
\text { prendas de vestir }\end{array}$ & 103 & $\begin{array}{l}\text { Rama } 3121 \\
\text { Elaboración } \\
\text { de otros } \\
\text { productos } \\
\text { alimenticios } \\
\text { para el } \\
\text { consumo } \\
\text { humano }\end{array}$ & 58262 & $\begin{array}{l}\text { Rama } 3111 \\
\text { Industria de } \\
\text { la carne }\end{array}$ & 175448 \\
\hline Ocottán & $\begin{array}{l}\text { Rama 5011 } \\
\text { Edificación }\end{array}$ & 52 & $\begin{array}{c}\text { Rama } 3112 \\
\text { Elaboración } \\
\text { de productos } \\
\text { lácteos }\end{array}$ & 12428 & $\begin{array}{c}\text { Rama } 3112 \\
\text { Elaboración } \\
\text { de productos } \\
\text { lácteos }\end{array}$ & 26066 \\
\hline Puerto Vallarta & $\begin{array}{c}\text { Rama } 9320 \\
\text { Hotelesy otros } \\
\text { servicios de } \\
\text { alojamiento } \\
\text { temporal }\end{array}$ & 71 & $\begin{array}{l}\text { Rama } 9320 \\
\text { Hoteles y otros } \\
\text { servicios de } \\
\text { alojamiento } \\
\text { temporal }\end{array}$ & 8755 & $\begin{array}{c}\text { Rama } 9320 \\
\text { Hoteles y otros } \\
\text { servicios de } \\
\text { alojamiento } \\
\text { temporal }\end{array}$ & 19721 \\
\hline Tepatitlán de Morelos & $\begin{array}{c}\text { Rama } 3119 \\
\text { Fabricación de } \\
\text { cocoa, } \\
\text { chocolate y } \\
\text { artículos } \\
\text { de confitería }\end{array}$ & 107 & $\begin{array}{l}\text { Rama } 3130 \\
\text { Industria de } \\
\text { las bebidas }\end{array}$ & 25992 & $\begin{array}{l}\text { Rama } 3130 \\
\text { Industria de } \\
\text { las bebidas }\end{array}$ & 58992 \\
\hline
\end{tabular}

Trab. por emp. = trabajadores promedio por empresa V.A.por emp. = valor agregado promedio por empresa (en miles de pesos) Prod.por emp.= producción bruta promedio por empresa (miles de pesos) Fuente: elaborado con base en INEGI, Censos Económicos de 1998. 
Si lo estudiamos desde el punto de vista de la producción bruta, la principal rama es la de comercio de alimentos al mayoreo, que genera $10 \%$ de la producción municipal, pero sólo da empleo a 706 personas (menos de $6 \%$ de la mano de obra urbana emplea da) . Adicionalmente, esta rama apenas si contribuye con $1.7 \%$ de la producción y $1.6 \%$ del valor agregado generado por esta rama en Jalisco. Finalmente, en el cuadro 6 se presentan los indicadores de las ramas económicas donde Zapottán El Grandetiene cierta especialización (medida por indicadores de empleo). Observe cómo en la mayoría de los casos hablamos de ramas constituidas por pequeñas empresas que generan escaso valor agregado. Incluso, en las ramas más importantes (aquellas que superan el millón de pesos de producción promedio por empresa), como es el comercio de alimentos al mayoreo, la fabricación de productos de aserra dero y los servicios para agricultura, sólo en el caso de los aserraderos estamos hablando de mejores indicadores respecto al promedio estatal, pero su contribución al valor agregado sectorial suele ser muy bajo, pues se ubica en los primeros eslabones de la cadena respectiva ${ }^{9}$

Para concluir con este apartado, cabe señalar que son claras las desventajas que presenta Zapotlán El Grande respecto a las otras ciudades medias del estado en la proyección de su plataforma de desarrollo económico en los próximos años. Sin embargo, así como hay condiciones desfavorables que requieren ser revertidas, hay otros indicadores de tipo socioeconómico que son positivos en este municipio y que deben convertirse en los principales activos para impulsar su desarrollo.

\footnotetext{
9 En el ámbito estatal, la rama de producción de aserraderos apenas contribuye con $11 \%$ del valor agregado en el subsector la industria de la madera, en tanto que la fabricación de muebles aporta $79 \%$, lo que da una clara idea de dónde se encuentra la rama productiva de mayor valor agregado. De igual manera, aun siendo una rama productiva importante en Zapotlán El Grande, sólo contribuye con $3.6 \%$ del valor agregado municipal.
} 


\section{Cuadro 6}

Indicadores económicos de las ramas de especialización de Zapottán El Grande (1998)

\begin{tabular}{|l|r|r|r|r|r|r|}
\hline & \multicolumn{3}{|c|}{ Zapotlán El Grande } & \multicolumn{3}{c|}{ Jalisco } \\
\hline & $\begin{array}{c}\text { Trab. } \\
\text { por } \\
\text { emp. }\end{array}$ & $\begin{array}{r}\text { V. A. } \\
\text { por } \\
\text { emp. }\end{array}$ & $\begin{array}{r}\text { Prod. } \\
\text { por } \\
\text { emp. }\end{array}$ & $\begin{array}{r}\text { Trab. } \\
\text { por } \\
\text { emp. }\end{array}$ & $\begin{array}{r}\text { V. A. } \\
\text { por } \\
\text { emp. }\end{array}$ & $\begin{array}{r}\text { Prod. } \\
\text { por } \\
\text { emp. }\end{array}$ \\
\hline Nixtamal y tortillas & 2 & 42 & 127 & 2 & 107 & 345 \\
\hline Aserraderos & 7 & 1158 & 1808 & 4 & 180 & 496 \\
\hline $\begin{array}{l}\text { Comercio alimentos } \\
\text { mayoreo }\end{array}$ & 18 & 2023 & 3164 & 11 & 2528 & 3684 \\
\hline $\begin{array}{l}\text { Comercio alimentos } \\
\text { menudeo especializado }\end{array}$ & 2 & 68 & 85 & 2 & 66 & 83 \\
\hline $\begin{array}{l}\text { Comercio no alimentos } \\
\text { menudeo especializado }\end{array}$ & 2 & 102 & 136 & 2 & 143 & 202 \\
\hline $\begin{array}{l}\text { Mantenimiento } \\
\text { automotriz }\end{array}$ & 3 & 61 & 116 & 3 & 72 & 151 \\
\hline Servicios agricultura & 27 & 848 & 1094 & 15 & 1223 & 5372 \\
\hline
\end{tabular}

Trab. por emp. $=$ trabajadores promedio por empresa

V. A.por emp.= valor agregado promedio por empresa (en miles de pesos)

Prod.por emp. $=$ producción bruta promedio por empresa (miles de pesos)

Fuente: elaborado con base en INEGI, Censos Económicos de 1998.

\section{Desarrollo socioeconómico}

Así como los indicadores de la actividad económica señalaron cierta vulnerabilidad de Zapotlán El Grande, en la situación socioeconómica existen características que fortalecen a este municipio para impulsar la planeación de su desarrollo. Es el caso del nivel de bienestar socioeconómico donde Zapotlán El Grande, a pesar de la poca consolidación de su aparato productivo, se encuentra en el rango más alto del estado, es superior al de los municipios de Los Altos (Lagos de Moreno y Tepatitlán). Lo anterior en gran parte tiene que ver con $\mathrm{I}$ hecho de que mientras Zapo- 
tán El Grande transitó antes de las actividades rurales hacia las urbanas, los municipios de Los Altos aún mantienen su mayor fortaleza productiva en la agroindustria (productos lácteos 0 avícolas) y obviamente muchas familias dependen económicamente del campo para su sostenimiento. Adicionalmente, esto provoca que buena parte de la población económicamente activa en esos municipios no perciba ingresos (por trabajar en explotaciones familiares) o bien, reciba ingresos menores a un salario mínimo. En función del indicador de bienestar socioeconómico, se puede decir que Zapotlán El Grande manifiesta buenas expectativas para atraer en el futuro próximo inversión hacia actividades manufactureras y de servicios de mayor valor agregado. Además, una fortaleza de las cinco ciudades medias del estado es el hecho de que todas tengan oferta de educación superior, pues en cada una de ellas se encuentra ubicado un Centro Universitario Regional de la Universidad de Guadalajara, así como otras instituciones educa tivas principalmente públicas. Lo anterior es multiplicador del desarrollo no sólo por la actividad educativa en sí, sino por la investigación que en ella se realiza y que podrá ser aprovechada por el aparato productivo actual y potencial. Por otro lado, en el cua dro 7 se observa la distribución del ingreso en las ciudades medias de Jalisco. Evidentemente, la que tiene el mejor indicador al respecto es Puerto Vallarta debido a la gran dinámica que ha alcanzado la actividad turística; le sigue Ocotlán y en tercer lugar podemos ubicar al municipio de Tepatitlán y Zapotlán El Grande. Definitivamente, el municipio que alcanza la distribución más desigual del ingreso es Lagos de Moreno por las razones señaladas anteriormente.

Es de destacar cómo Tepatitlán, que tenía indicadores muy inferiores a los de Zapotlán El Grande en 1980, ha revertido totalmente esta situación veinte años después, al grado de que se ubica como el cuarto municipio que mejor distribuye el ingreso y el quinto que tiene un ingreso promedio más elevado. Por su parte, Zapotlán El Grande prácticamente ha ido al parejo de la dinámica estatal, de manera que no ha mejorado sus posiciones en 


\section{Cuadro 7}

Distribución del ingreso en las ciudades medias de Jalisco

\begin{tabular}{|c|c|c|c|c|c|}
\hline & $\begin{array}{l}\text { Zapotlán } \\
\text { E Grande }\end{array}$ & $\begin{array}{c}\text { Lagos } \\
\text { de Moreno }\end{array}$ & Ocotlán & $\begin{array}{l}\text { Puerto } \\
\text { Vallarta }\end{array}$ & Tepatitlán \\
\hline \multirow{2}{*}{$\begin{array}{l}\text { Número de personas } \\
\text { ganan menos de } 2 \\
\text { salarios mínimos } \\
\text { por } 1 \text { que gana más } \\
\text { de } 5 \text { salarios mínimos }\end{array}$} & 809000 & 809000 & 809000 & 809000 & 809000 \\
\hline & 2074 & 48186 & 1852 & $\begin{array}{lll}13 & 2 & 1\end{array}$ & 6484 \\
\hline Lugar en el estado & 5665 & 184321 & $\begin{array}{lll}4 & 5 & 4\end{array}$ & $\begin{array}{lll}3 & 1 & 2\end{array}$ & 34196 \\
\hline $\begin{array}{l}\text { Número de personas } \\
\text { ganan menos de } 2 \\
\text { salarios mínimos } \\
\text { por } 1 \text { que gana más de } \\
10 \text { salarios mínimos }\end{array}$ & $* \quad * 13$ & $* * 16$ & $* \quad * 12$ & $* \quad * 5$ & $* \quad * 11$ \\
\hline Lugar en el estado & $* \quad * 7$ & $* \quad * 13$ & $* \quad * \quad 5$ & $* \quad * \quad 2$ & $* * 4$ \\
\hline $\begin{array}{l}\text { Lugar en el estado } \\
\text { en ingreso } \\
\text { promedio }\end{array}$ & $\begin{array}{lll}7 & 7 & 8\end{array}$ & 235125 & $\begin{array}{lll}4 & 5 & 4\end{array}$ & $\begin{array}{lll}3 & 1 & 1\end{array}$ & 30225 \\
\hline
\end{tabular}

Fuente:elaborado con base en datos de INEGI, censos de población de 1980,1990 y 2000.

estos veinte años. Por el contrario, en el caso de ingreso promedio, mientras en 1980 estaba en el séptimo lugar, para el 2000 bajó al octavo.

Lo anterior es una consecuencia evidente del menor dinamismo económico que este municipio ha tenido en los últimos años en comparación con lo que ha sucedido en las otras ciudades medias de Jalisco.

\section{Contaminación y vulnerabilidad}

Las actividades económicas presentes y futuras que se establezcan en una región indudablemente presionan sobre los recursos de la 
misma e impactan en su potencial desarrollo. En este apartado consideramos dos situaciones distintas:

La primera tiene que ver con la potencialidad contaminante que las actividades económicas urbanas tienen en el agua, aire y suelo de las ciudades medias aquí estudiadas, medido esto por los niveles de participación de cada rama en el ámbito del municipio.

La segunda situación se refiere a cómo los procesos socioeconómicos que se desarrollan en el municipio presionan y generan vulnerabilidad tanto en el medio natural como en el social y en el productivo.

En lo que respecta al potencial contaminante de las actividades económicas urbanas (cuadro 8), encontramos que la mayor presión al aire se encuentra en Lagos de Moreno, aunque ésta se puede considerar como media baja Zapotlán El Grande se ubicaría en

\section{Cuadro 8}

Potencial contaminante de las actividades económicas urbanas de las ciudades medias

\begin{tabular}{|l|c|c|c|}
\hline Municipio & Aire & Agua & Suelo \\
\hline Zapottán el Grande & 1.2947 & 1.5147 & 1.2349 \\
Lagos de Moreno & 1.4016 & 1.6531 & 1.3098 \\
Ocotlán & 1.2422 & 1.6348 & 1.2194 \\
Puerto Vallarta & 1.1699 & 1.6685 & 1.1672 \\
Tepatitlán de Morelos & 1.3154 & 1.5993 & 1.3128 \\
\hline
\end{tabular}

Criterios:

Más de 2.2, contaminación muy alta

Del.8 a 2.2, contaminación alta

De 1.5 a 1.8, contaminación media alta

Del.3 a 1.5, contaminación media baja

De 1 a 1.3, contaminación baja

Fuente: elaborado con base en INEGI, Censos Económicos de 1998,y matriz de potencial contaminante por rama productiva explicada en el anexo II. 
el tercer lugar con un potencial que es bajo y que, por lo tanto, no se convierte en un freno para el impulso de nuevas actividades económicas.

En lo que concierne al agua es donde mayor problema presentan las ciudades medias con niveles muy parecidos de contamina ción potencial, que en todos los casos llega a ser media alta. Sin embargo, de las cinco ciudades, Zapotlán El Grande parece ser el que tiene menos presión. Finalmente, en contaminación potencial del suelo, prácticamente todos tienen una presión baja o si acaso media baja, siendo la mayor presión en los municipios de Los Altos (Tepatitlán y Lagos de Moreno). En los otros indicadores mostrados en el cuadro 9, Zapotlán El Grande compite en condiciones similares con las demás ciudades medias, y se observa que el aspecto más preocupante es la presión que genera el sistema productivo sobre los recursos ambientales, principalmente por su actividad pecuaria. Sin embargo, esta situación de fuerte presión de la actividad productiva también se manifiesta en los otros casos de las ciudades medias de Jalisco.

En cuanto a la presión sobre el sistema natural, la situación de Zapottán El Grande es media; el mayor problema es la acidez y lo arcilloso de sus suelos, lo que dificulta el desarrollo de algunas actividades agrícolas. Finalmente, el sistema social ejerce también una alta presión sobre los recursos ambientales, sobre todo en lo que respecta a la elevada urbanización que existe en el municipio, pero al igual que en las otras variables, esta situación no difiere mucho de las demás ciudades medias y en todo caso es, como dice la gente del lugar, un precio que se tiene que pagar por el desarrollo.

Por lo que toca a la vulnerabilidad que manifiestan los tres sistemas (natural, social y productivo), la situación va de media a baja, existe por lo tanto relativamente pocos problemas en este sentido. Por ejemplo, en el sistema natural una vez más la mayor vulnerabilidad se muestra en la textura de los suelos que limitan la productividad de las actividades agrícolas. En el sistema social no hay mayores problemas de vulnerabilidad salvo el caso de los 


\section{Cuadro 9}

Presiones y vulnerabilidad sobre los sistemas natural, social y productivo en las ciudades medias de Jalisco en 1999

\begin{tabular}{|c|c|c|c|c|c|}
\hline \multicolumn{6}{|c|}{ Indicador* } \\
\hline $\begin{array}{l}\text { Presiones y } \\
\text { vulnerabilidad }\end{array}$ & $A^{* *}$ & $B C$ & D & & $\begin{array}{l}\text { Áreas de mayor preocupación } \\
\text { en Zapotlán El Grande*** }\end{array}$ \\
\hline $\begin{array}{l}\text { Presión del } \\
\text { sistema natural }\end{array}$ & 3 & \begin{tabular}{ll|}
3 & 4
\end{tabular} & 33 & 3 & $\begin{array}{l}\text { - } 1147 \text { hectáreas de superficie incendiada. } \\
\text { - } 83 \% \text { de superficie con suelos pobres en } \\
\text { materia orgánica } \\
\text { - Sobrepastoreo ( } 149000 \text { EM Mcal/ 1000) } \\
\text { - 0\% de sullo con textura no arcillosa } \\
\text { - 95.04\% de sudos ádos } \\
\text { - Contaminación del agua subterránea } \\
\text { - } 569 \text { establecimientos manufactureros o de } \\
\text { servicios en giros contaminantes } \\
\text { - Contaminación por descargas municipales } \\
\text { (25 } 912 \text { viviendas conectadas al drenaje } \\
\text { municipal) } \\
\text { - } 110 \text { toneladas diarias de residuos sólidos }\end{array}$ \\
\hline $\begin{array}{l}\text { Vulnerabilidad } \\
\text { del sistema } \\
\text { natural }\end{array}$ & 3 & \begin{tabular}{ll|}
5 & 2
\end{tabular} & 32 & 2 & $\begin{array}{l}\text { - Vulnerabilidad por diversidad beta } \\
\text { (índice de diversidad beta 1.82) } \\
\text { - Vulnerabilidad del sudo por textura }\end{array}$ \\
\hline $\begin{array}{l}\text { Presión del } \\
\text { sistema social }\end{array}$ & 4 & \begin{tabular}{|l|l|}
4 & 4
\end{tabular} & 4 & 4 & $\begin{array}{l}\text { - } 2.57 \text { de coefi iente porcentual de superficie } \\
\text { urbana sobre superficietotal } \\
\text { - } 49.00 \text { índice de urbanización } \\
\text { - } 1.39 \text { de concentración urbana } \\
\text { - Contaminación por descargas municipales } \\
\text { (25 } 912 \text { viviendas conectadas al drenaje } \\
\text { municipal) } \\
\text { - } \mathbf{1 1 0} \text { toneladas diarias de residuos sólidos } \\
\text { - } \mathbf{1 3} \mathbf{4 5 6} \text { vehículos }\end{array}$ \\
\hline $\begin{array}{l}\text { Vulnerabilidad } \\
\text { del sistema social }\end{array}$ & 2 & 22 & 22 & 2 & $\begin{array}{l}\text { - Subutilización de bibliotecas por consulta } \\
\text { (1.1 consulta/ usuario/ año) } \\
\text { - Inaccesibilidad de servicios de seguridad social } \\
\text { - Índice de masculinidad } \\
\text { ( } 92.6 \text { hombres por cada } 100 \text { mujeres) }\end{array}$ \\
\hline
\end{tabular}


Continuación del cuadro 9

\begin{tabular}{|c|c|c|c|c|}
\hline \multicolumn{5}{|c|}{ Indicador* } \\
\hline $\begin{array}{l}\text { Presiones y } \\
\text { vulnerabilidad }\end{array}$ & $A^{* *}$ & B C & $D E$ & $\begin{array}{l}\text { Áreas de mayor preocupación } \\
\text { en Zapotán El Grande*** }\end{array}$ \\
\hline $\begin{array}{l}\text { Presión del } \\
\text { sistema } \\
\text { productivo }\end{array}$ & 5 & $\begin{array}{lll}5 & 4\end{array}$ & 45 & $\begin{array}{l}5 \text { - Presión por producción pecuaria } \\
\text { (174 } 376 \text { toneladas al año) } \\
\text { - Presión por cabezas de ganado } \\
\text { ( } 809 \text { 969 cabezas) } \\
\text { - Presión por establecimientos de la industria } \\
\text { manufacturera } \\
\text { - Presión por personal ocupado en servicios } \\
\text { - Presión por establecimi entos en servicios } \\
\text { - Presión por consumo urbano } \\
\text { de energía éédrica (27 } 163 \mathrm{kw} / \mathrm{hr} \text { ) }\end{array}$ \\
\hline $\begin{array}{l}\text { Vulnerabilidad } \\
\text { del sistema } \\
\text { productivo }\end{array}$ & 2 & 22 & 22 & 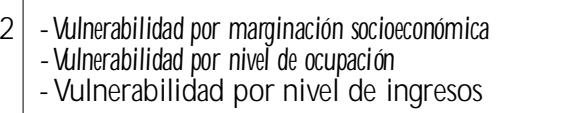 \\
\hline
\end{tabular}

${ }^{*}$ Los valores van de 1 a 5, donde 1 es muy baja presión o vulnerabilidad, 2 es baja, 3 es media, 4 es alta y 5 es muy alta presión o vulnerabilidad.

${ }^{* *} \mathrm{~A}=$ Zapottán El Grande

$B=$ Lagos de Moreno

$C=0$ cotlán

D = Puerto Vallarta

$\mathbf{E}=$ Tepatitlán

*** Sólo se enlistan las áreas con valores de 4 y 5. Las áreas en cursivas son las que tienen un indicador de valor 5 .

Fuente: U. de G.,Gobierno de Jalisco, Semarnat (2000), Indicadores municipales de susten tabilidad. La metodología para la definición de los indicadores se encuentra en dicho documento.

servicios de seguridad pública, en tanto que en el sistema productivo la vulnerabilidad proviene principalmente de que si bien $\mathrm{Za}$ potlán El Grande, como cabecera municipal, tiene un alto nivel de bienestar socioeconómico, existe igualmente una situación preocupante de desigualdad, aun cuando, como ya se vio antes, esto no difiere mucho con relación al resto de los municipios de jalisco.

Con todo lo anterior, podemos decir que en lo que respecta a los niveles de presión sobre los recursos ambientales y la vulnera bilidad que manifiestan los sistemas natural, social y productivo, 
no hay grandes diferencias en lo general entre las cinco ciudades medias de Jalisco. Aún así, Zapottán el Grande tiene cierta ventaja al constituirse en un sitio con menores presiones sobre sus recursos naturales (exceptuando el problema delicado que tiene con relación al agua), lo que lo hace potencialmente más atractivo en ciertas áreas para la inversión.

\section{Conclusiones}

Las regiones de reciente urbanización como la aquí analizada tienen hoy el gran reto de ganar espacios en las redes de competitividad global. Mejorar de nivel en esas redes sí es factible, aunque es un proceso lento y requiere grandes esfuerzos de sus actores principales para impulsar procesos de reestructuración en sus condiciones socioeconómicas que les permitan insertarse competitivamente en los flujos primarios o por lo menos secundarios del capital. Hacer esto permitirá paulatinamente a los actores locales modificar el marco institucional y sobre todo las pautas culturales que norman a la región en aquellos puntos en que las mismas sean incompatibles con el pretendido desarrollo, pero también fortalecer las que se convierten en una ventaja comparaiva de la región respecto a otras con las que compite. En todo caso, lo primero que deben solucionar los principales líderes locales es definir desde dentro el tipo de desarrollo que se quiere, reconociendo que cada vez es más difícil progresar al margen de los flujos de competencia global, pero también que ningún desarrollo verdadera mente positivo para la región puede venir exclusivamente de fuera. En segundo lugar, dada la lentitud con que es posible cambiar algunas cosas y la necesidad de obtener resultados en el corto plazo, los gobiernos nacionales, pero principalmente los regiona les y locales (que por el proceso de la globalización demandante de flexibilidad y velocidad de respuesta, muchas veces sustituyen a los Estados nacionales en la función de atraer y gestionar los flujos de capital internacional [Boisier, 1999:38]), enfrentan la dis- 
yuntiva de atraer al capital trasnacional, dando todas las facilida des aun cuando éstas afecten los equilibrios económicos, sociales, culturales y/ 0 ambientales de sus regiones, o establecer los límites de actuación del capital, arriesgándose con ello a rezagarse en la carrera frente a otras regiones con las que compiten, y perder así la oportunidad de por lo menos crear empleo y crecer. Solucionar esto no ha sido nada fácil para la mayoría de las regiones que se encuentran en esa situación. De hecho, requiere trabajar con dos planes, uno de corto plazo, no muy propenso al desarroIlo, aunque sí al crecimiento económico, y otro de largo plazo que sea vislumbrado como proyecto de desarrollo endógeno. En este último, la región (más bien, sus actores principales) requiere actuar como cuasiempresa (Boisier, 1999:44), de manera que se fortalezca su capacidad interna, mediante la creación y multiplica ción de ventajas competitivas.

En el caso de Jalisco, son las ciudades medias las que se constituyen en la parte fundamental del proceso de desarrollo regional que se necesita implementar de cara al siglo XXI. En un estado caracterizado por la excesiva concentración de la vida económica, política y social en la ciudad de Guadalajara y su zona conurbada, las ciudades medias son el mecanismo para disminuir tal concentración y fomentar el desarrollo de sus distintas regiones.

Por ello, como lo reconoce el propio gobierno de Jalisco, estas ciudades medias son los polos de desarrollo de sus respectivas regiones. Sin embargo, en esta entidad apenas si se observa un lento proceso de difusión de las actividades económicas de Gua dalajara hacia las ciudades medias, e incluso el mismo gobierno admite que no han desarrollado todavía los atributos para ser atractivas a la inversión. Aun así, los cinco centros urbanos del estado que pueden considerarse ciudades medias compiten hoy por atraer capitales y proyectar su proceso de desarrollo en función de las nuevas tendencias internacionales de competitividad. Ante ello, deben incrementarse los trabajos que presenten las características actuales de cada uno de los centros urbanos mencionados para ver cómo ello condiciona sus perspectivas a futuro. 
En ese sentido, $s$ debe destacar que las ciudades medias de Ja lisco presentan en general niveles similares de evolución económica, aunque cada una destaca en sus respectivas actividades, las que dan mayor o menor relevancia a la ciudad. En el caso particular de Zapotlán El Grande, éste tiene claras desventajas fundamentadas en la inexistencia de ramas económicas de gran especialización para fomentar clusters regionales endógenos, así como la excesiva concentración de sus actividades en ramas de poco valor agregado 0 muy relacionadas con la dotación de recursos naturales.

Si consideramos que las actividades económicas capaces de fomentar el desarrollo regional en este mundo globalizado son aquéllas que proveen servicios de alto valor agregado fundadas en la economía del aprendizaje, Zapotlán El Grande requiere trabajar mucho para promover dichas industrias porque las que hoy tiene no presentan esos rasgos. Sin embargo, la situación puede revertirse en la medida en que el municipio aproveche sus activos, para convertirlos en ventajas que impulsen el desarrollo del sur de Jalisco. Entre éstos se encuentran su ubicación estratégica en el tránsito entre Guadalajara y Manzanillo, los excelentes canales de comunicación, el acceso a todos los servicios de la tecnología de la información, el crecimiento de su capacidad para proveer educación superior de mayor calidad, aś como la poca dispersión de la población en el ámbito del municipio.

Igualmente, queda para una posterior investigación identificar si sus patrones socioculturales e institucionales son propicios para fomentar el desarrollo endógeno regional o algunos de sus rasgos pueden obstaculizar ciertas potencialidades.

En todo caso, la gente de Zapotlán El Grande y sobre todo sus principales líderes deberán estar preparados para: 1) impulsar un tejido empresarial sólido con una clara visión de las necesidades competitivas presentes y futuras; 2) consolidar empresas de control local y con gran integración económica con el aparato productivo regional, por encima de aquéllas controladas externamente;3) diversificar sus actividades económicas en ramas capaces de ser consolidadas para ofrecer bienes y servicios de alto valor agregado; 
4) profundizar una real vinculación entre el aparato productivo y las instituciones de educación superior para generar investigación pertinente y de calidad que impulse la innovación y el crecimiento del capital social de la región; 5) consolidar las instituciones sociales regionales que fomenten la participación de toda la comunidad, el consenso, las relaciones de confianza y, en general, el acrecentamiento de los activos relacionales locales

Claro que lo anterior debe ir aparejado de dos condiciones bá sicas que salen del control propio de la región: primero, la estabilidad macroeconómica y las políticas impulsadas por el gobierno federal y estatal para que la región reciba mayores recursos y los pueda manejar en función de sus necesidades y objetivos, y segundo, la consolidación del sistema financiero que permita $\mathrm{e}$ flujo de capitales

Sólo en la medida en que la población de Zapotlán El Grande aproveche sus fortalezas y oportunidades para consolidar sus instituciones, así como reconozca sus debilidades y esté en disposición de modificarlas, podrá consolidarse en los próximos años como una de las ciudades medias de Jalisco.

Recibido en enero de 2004 Revisado en mayo de 2004

\section{Bibliografía}

Amin, Ash (1998), "Una perspectiva institucionalista sobre el desarrollo económico regional", Ekonomiaz, no. 41, segundo cua trimestre, pp. 68-89.

Arroyo, Jesús (1995), "Políticas urbanas, desarrollo industrial y riesgos ecológicos en la Zona Metropolitana de Guadalajara", Guadalajara, INESER, Universidad de Guadalajara, inédito. 
y LuisArturo Velásquez (1997), "Introducción", en Luis Arturo Velásquez y Jean Papail, Migrantes y transformación económica sectorial (cuatro ciudades de occidente), Guadalajara, Universidad de Guadalajara.

Boisier, Salvador (1999), Teorías y metáforas sobre desarrollo territorial, Santiago de Chile, CEPAL.

Castells, Manuel [1996] (2001), La era de la información:economía, so ciedad y cultura. Vol. I. La sociedad red, México, Siglo xxı Editores.

CEO (Centro de Estudios de Opinión), Universidad de Guadalajara (2001), Encuesta internacional sobre medio ambiente Caso:M éxico, vitrina metodológica, México.

García, Haydeé (1997), “Comunicación, vida cotidiana e identidades urbanas en S. L. P., en tiempos de globalización", Ra zón y Palabra, julio, disponible en: http:/ / www.cem.itesm.mx/ dacs/ publicaciones/ logos/ mcluhan/ mcluhan.html

García, Ma. Luisa (1997), "Impactos ambientales de la apertura económica en Jalisco. Análisis de las características contaminantes de las empresas de exportación", en Jesús Arroyo y Adrián de León (comps.), La internacionalización de la economía jalis ciense, Guadalajara, Universidad de Guadalajara, UCLA Program on Mexico y Juan Pablos Editor.

Garza, Gustavo (1998), "Evolución del sistema de ciudades en México, 1960-1995", Demos, no. 11, pp. 23-25.

Gobierno del Estado de Jalisco ( 2001), Plan Estatal de Desarrollo 2001 2006, México.

Gobierno del Estado de San Luis Potosí, Secretaría de Desarrollo Social, Universidad Autónoma de San Luis Potosí (2001),Plan de Desarrollo U rbano del Estado de San Luis Potosí, México. 
Granovetter, Mark [1985](2002), "Economic Action and Social Structure: The Problem of Embeddedness", en M. Granovetter y R. Swedberg, The Sociology of Economic Life, Boulder Westview Press, pp. 51-76.

INEGI (Instituto Nacional de Estadística, Geografía e Informática)

(1970), Censo de Población y Vivienda 1970, México.

(1980), Censo de Población y Vivienda 1980, México.

(1990), Censo de Población y Vivienda 1990, México.

(1994), Censos Económicos 1994, México.

(1996), Anuario Estadístico de Estado dejalisco, México.

(1999), Censos Económicos 1998, México.

(2000), Censo de Población y Vivienda 2000, México.

(2001), Información Estadística por Entidad Federativa, Dirección General de Estadística, México, disponible en: http:/ / www.inegi.gob.mx/ entidades/ espanol/ fentida des.html

(2002), Sistema de Cuentas Nacionales de México. Producto Inter no Bruto por Entidad Federativa,1993-2000, México.

Macías,Alejandro (2003), “Los clusters económicos en Zapottán El Grande, Jalisco, como medios potenciales para alcanzar el desarrollo sustentable", El Cotidiano, no. 121, septiembre-octubre, pp. 93-106.

Porter, Michael (1999), "Clusters y competencia", en Michael Porter, Ser competitivo, Barcelona, Deusto, pp. 203-288. 
Portes, Alejandro y P. Landolt (1996), "The Downside of Social Capital", TheAmerican Prospect, no. 26. Disponible: http:/ / www.prospectorg/ print/ V4/ 26/ portes-r.html

Presidencia de la República (1995), Plan Nacional de Desarrollo 19952000, México.

(2001), Plan Nacional de Desarrollo 2001-2006, México.

Putnam, Robert (1993), "The Prosperous Community. Social Capital and Public Life", TheAmerican Prospect, no. 13, disponible en: http:/ / www .prospectorg/ print/ V4/ 13/ putnam-r.html

Quijada, Rodrigo (2001), “El 'Urban Mobility Study': la situación del transporte urbano en los Estados Unidos", Tranvía, revista de transporte, no. 10, junio, disponible en:

http:/ / www.revistatranvia.cl/ tv10/

Richardson, Harry (1975), Elementos de economía regional, Madrid, Alianza Editorial.

SEDESOL (Secretaría de Desarrollo Social) (2000), Ordenami ento terito rial: base para e desarrollo regional y urbano, noviembre, México, disponible en: http:/ / www.sedesol.gob.mx/ nove2000/ folleto/ ordenamiento.pdf

Storper, Michael [1997] (1998), "Las economías regionales como activos relacionales", Ekonomiaz, no. 41, segundo cuatrimestre, pp. 11-45.

Van Young, Eric (1992), "Introduction: Are Regions Good to Think?", en E. Van Young (eds.), Mexico's Regions Comparative His tory and Development, San Diego, University of California, Center for U.S.-Mexican Studies, pp. 1-36. 


\section{Anexo I \\ Metodología para la determinación \\ de ramas económicas especializadas}

Para la definición de la especialización de los sectores manufacturero, servicios y comercio se consideraron cuatro criterios tomando en cuenta la mano de obra ocupada en cada una de las ramas económicas identificadas por el Instituto Nacional de Estadística, Geografía e Informática (INEGI) en los censos económicos de 1994 y 1998:

1. Se calculó el promedio simple y la desviación estándar correspondiente a cada uno de los 124 municipios del estado de Jalisco en cada rama económica. Con estos dos datos, se identificaron los municipios que estaban en una desviación estándar por arriba del promedio y se les asignaron 5 puntos; a los que estaban dos o más desviaciones encima del promedio se les asignaron 10 puntos.

2. El segundo criterio fue la técnica del cociente de localización (C. L.), que se define por la fórmula siguiente:

$$
\begin{array}{r}
\text { C. } L_{1}=e_{i} / e \\
E_{i} / E
\end{array}
$$

Donde:

$$
\begin{aligned}
& e_{i}=\text { empleo local (en el municipio) en la i-ésima rama industrial } \\
& e=\text { total de empleo local } \\
& E_{i}=\text { empleo estatal en la } i \text {-ésima rama industrial } \\
& E=\text { total de empleo estatal }
\end{aligned}
$$

Cuando existe un C. L.> 1, hay un índice sobrante de tra bajadores, es decir, "la diferencia entre el verdadero empleo industrial de la región (en este caso del municipio) y la partcipación prorrata de la región (e municipio) en el empleo de la industria nacional (en este caso de la rama industrial esta 
tal)" (Richardson, 1975). Esta rama económica, por consiguiente, se convierte en sector base económica para el municipio, pues se supone que exporta parte de su producción a otros municipios. Para efectos de este trabajo, cuando el municipio tenía un coeficiente de localización de entre 1 y 2 se le asignaron 5 puntos, y si superaba esa cifra, se le dieron 10 puntos.

3. En el tercer criterio se consideró la participación de los municipios con respecto a la mano de obra estatal en cada rama. $\mathbf{S i}$ el municipio tenía entre 5 y 10\% de participación, se le asignaron 5 puntos y más de $10 \%$ de participación se le asignaron 10 puntos.

4. Finalmente, el cuarto criterio consistió en el porcentaje de participación de la mano de obra ocupada en cada rama productiva con respecto al total de la mano de obra ocupada en actividades económicas urbanas (manufacturas, servicios y comercio) en el municipio. Así, si la rama económica tenía entre 5 y 10\% de la mano de obra ocupada en actividades urba nas en los municipios, se le asignaron 5 puntos y si eran más de $10 \%$ se le asignaron 10 puntos. Enseguida se sumaron los cuatro criterios y se identificaron los niveles de especialización según el siguiente criterio: si la rama económica i en el municipio j tuvo entre 25 y 40 puntos, se le identificó como de alta especialización; si estaba entre 15 y 20 puntos, la especialización era media; si fue entre 5 y 10 puntos, la especialización fue baja y si tuvo cero puntos, entonces se consideró como una rama económica de especialización nula. 


\section{Anexo II \\ Determinación del potencial contaminante de las actividades económicas urbanas}

Para el cálculo de este indicador se realizó lo siguiente:

1. Se utilizó la matriz de impacto ambiental potencial contaminante por rama de actividad económica que el Instituto de Estudios Económicos y Regionales de la Universidad de Gua dalajara elaboró tomando en cuenta las metodologías y listas de los trabajos de Arroyo (1995) y García (1997) para obtener una clasificación preliminar por potencial contaminante al aire y suelo, así como la experiencia empírica del Centro de Ingeniería Ambiental del Departamento de Ingeniería y Proyectos del Centro Universitario de Ciencias Exactas e Ingeniería de la Universidad de Guadalajara, para que, a partir de las listas anteriores, se elaborara la matriz en el caso del agua.Da do que no todas las ramas económicas contempladas por el INEGI en el censo económico de 1999 fueron incluidas en tal matriz, se completaron las faltantes con base en la misma ma triz ya generada y en la identificación de características afines para las ramas económicas no contempladas. La matriz generada asignó valores entre 1 y 3 a cada rama económica en las tres variables: contaminación al aire, al agua y a la tierra, donde 1 significó contaminación potencial baja, 2 contaminación potencial media y 3 contaminación potencial alta. La tabla resultante es la siguiente: 
Nivel de potencial contaminante por rama económica

\begin{tabular}{|c|c|c|c|c|c|c|c|c|c|c|c|}
\hline \multirow{2}{*}{$\begin{array}{c}\text { Rama } \\
\text { Económica }\end{array}$} & \multicolumn{3}{|c|}{ NPC } & \multirow{2}{*}{\begin{tabular}{|c|} 
Rama \\
Económica
\end{tabular}} & \multicolumn{3}{|c|}{ NPC } & \multirow{2}{*}{\begin{tabular}{|l|} 
Rama \\
Económica
\end{tabular}} & \multicolumn{3}{|c|}{ NPC } \\
\hline & Aire & Agua & Suelo & & Aire & Agua & Suelo & & Aire & Agua & Suelo \\
\hline 3111 & 2 & 2 & 1 & 3612 & 2 & 1 & 1 & 7112 & 2 & 1 & 1 \\
\hline 3112 & 2 & 2 & 1 & 3620 & 2 & 1 & 1 & 7113 & 1 & 1 & 1 \\
\hline 3113 & 2 & 2 & 1 & 3691 & 3 & 2 & 1 & 7120 & 1 & 2 & 1 \\
\hline 3114 & 2 & 1 & 1 & 3710 & 3 & 3 & 2 & 7130 & 2 & 1 & 1 \\
\hline 3115 & 2 & 2 & 1 & 3720 & 3 & 3 & 3 & 7140 & 1 & 1 & 1 \\
\hline 3116 & 2 & 1 & 1 & 3811 & 2 & 3 & 3 & 8211 & 1 & 1 & 1 \\
\hline 3117 & 2 & 3 & 1 & 3812 & 2 & 2 & 2 & 8212 & 1 & 1 & 1 \\
\hline 3118 & 3 & 3 & 2 & 3813 & 2 & 2 & 2 & 8311 & 1 & 1 & 1 \\
\hline 3119 & 2 & 2 & 1 & 3814 & 2 & 2 & 2 & 8312 & 1 & 1 & 1 \\
\hline 3121 & 2 & 2 & 1 & 3821 & 2 & 2 & 2 & 9211 & 1 & 1 & 1 \\
\hline 3122 & 2 & 2 & 1 & 3822 & 2 & 2 & 2 & 9221 & 2 & 3 & 1 \\
\hline 3130 & 2 & 2 & 1 & 3823 & 1 & 2 & 1 & 9231 & 1 & 3 & 3 \\
\hline 3140 & 2 & 2 & 1 & 3831 & 1 & 2 & 1 & 9241 & 1 & 1 & 1 \\
\hline 3211 & 2 & 2 & 2 & 3832 & 1 & 2 & 1 & 9250 & 1 & 1 & 1 \\
\hline 3212 & 1 & 2 & 2 & 3833 & 1 & 2 & 1 & 9290 & 1 & 1 & 1 \\
\hline 3213 & 1 & 2 & 2 & 3841 & 2 & 3 & 2 & 9310 & 1 & 2 & 1 \\
\hline 3214 & 1 & 2 & 2 & 3842 & 2 & 3 & 2 & 9320 & 1 & 2 & 1 \\
\hline 3220 & 1 & 1 & 1 & 3850 & 1 & 2 & 1 & 9411 & 1 & 1 & 1 \\
\hline 3230 & 2 & 3 & 3 & 3900 & 1 & 2 & 1 & 9421 & 1 & 1 & 1 \\
\hline 3240 & 1 & 1 & 1 & 5011 & 2 & 1 & 2 & 9491 & 1 & 2 & 1 \\
\hline 3311 & 1 & 1 & 1 & 5012 & 2 & 1 & 2 & 9510 & 2 & 3 & 2 \\
\hline 3312 & 1 & 1 & 1 & 5013 & 2 & 2 & 2 & 9520 & 1 & 1 & 1 \\
\hline 3320 & 1 & 2 & 1 & 5014 & 2 & 1 & 2 & 9530 & 2 & 2 & 1 \\
\hline 3410 & 3 & 3 & 2 & 5020 & 2 & 1 & 2 & 9540 & 1 & 1 & 1 \\
\hline 3420 & 1 & 3 & 1 & 5030 & 2 & 1 & 2 & 9611 & 1 & 2 & 2 \\
\hline 3511 & 3 & 3 & 3 & 6110 & 2 & 1 & 2 & 9612 & 2 & 3 & 2 \\
\hline 3512 & 3 & 3 & 3 & 6120 & 1 & 1 & 1 & 9613 & 1 & 1 & 1 \\
\hline 3513 & 2 & 3 & 2 & 6140 & 1 & 1 & 1 & 9710 & 2 & 3 & 2 \\
\hline 3521 & 2 & 3 & 3 & 6210 & 1 & 1 & 1 & 9720 & 2 & 2 & 1 \\
\hline 3522 & 3 & 3 & 3 & 6220 & 1 & 1 & 1 & 9731 & 2 & 3 & 2 \\
\hline 3530 & 3 & 3 & 3 & 6230 & 1 & 1 & 1 & 9732 & 2 & 3 & 1 \\
\hline 3540 & 3 & 3 & 3 & 6240 & 1 & 1 & 1 & 9733 & 2 & 3 & 1 \\
\hline 3550 & 3 & 3 & 2 & 6250 & 1 & 1 & 1 & 9740 & 1 & 1 & 1 \\
\hline 3560 & 2 & 3 & 2 & 6260 & 2 & 2 & 3 & 9750 & 1 & 1 & 1 \\
\hline 3611 & 3 & 2 & 1 & 7111 & 2 & 1 & 2 & 9790 & 1 & 1 & 1 \\
\hline
\end{tabular}

NPC = nivel potencial de contaminación. 
2. Enseguida se calculó el promedio ponderado de contamina ción potencial en cada municipio y por cada variable, usando como ponderador la mano de obra ocupada en cada rama económica. Cabe señalar que una debilidad de esta decisión es que puede haber industrias muy contaminantes que utilicen poca mano de obra y sean intensivas en capital o viceversa, pero se consideró que aun con esta debilidad, podría dar un acercamiento al objetivo buscado de medir la vulnerabilidad ambiental que el municipio tenga con base en sus actuales actividades económicas urbanas

3. Los valores obtenidos, por tanto, estuvieron en el rango de 1 y 3. Así que se tomó el siguiente criterio:

Valores superiores a 2.2: contaminación potencial muy alta. Valores entre 1.8 y 2.2: contaminación potencial alta. Valores entre 1.5 y 1.8: contaminación potencial media alta. Valores entre 1.3 y 1.5: contaminación potencial media baja Valores entre 1 y 1.3: contaminación potencial baja. 